\title{
Correction to: Citrate high volume on-line hemodiafiltration modulates serum Interleukin- 6 and Klotho levels: the multicenter randomized controlled study "Hephaestus"
}

\author{
Francesco Pizzarelli ${ }^{1}$ D . Vincenzo Cantaluppi ${ }^{2} \cdot$ Vincenzo Panichi $^{3} \cdot$ Alessandro Toccafondi $^{1} \cdot$ Giuseppe Ferro $^{1}$. \\ Serena Farruggio ${ }^{2}$. Elena Grossini ${ }^{4}$. Pietro Claudio Dattolo ${ }^{1}$ - Vincenzo Miniello ${ }^{5} \cdot$ Massimiliano Migliori $^{3}$. \\ Cristina Grimaldi ${ }^{6}$. Aldo Casani ${ }^{7}$. Maurizio Borzumati ${ }^{8} \cdot$ Stefano Cusinato $^{9} \cdot$ Alessandro Capitanini $^{5}$. \\ Alessandro Quercia ${ }^{10}$. Oliviero Filiberti ${ }^{11} \cdot$ Lucia Dani $^{12} \cdot$ On behalf of the Hephaestus study group ${ }^{1}$
}

Published online: 24 February 2021

(c) Italian Society of Nephrology 2021

\section{Correction to: Journal of Nephrology https://doi.org/10.1007/s40620-020-00943-6}

While typesetting the article, the conclusion section was incorrectly published. The correction conclusion section was copied below:

Citrate buffer modulated IL-6, hsCRP and Klotho levels during high volume OL-HDF. These results are not attributable to differences in the dialysis technology that was applied and may suggest a potential biological effect of citrate on CKD-associated inflammatory state.

The original article has been corrected.

Publisher's Note Springer Nature remains neutral with regard to jurisdictional claims in published maps and institutional affiliations.
The original article can be found online at https://doi.org/10.1007/ s40620-020-00943-6.

Francesco Pizzarelli

fpizzarelli@yahoo.com

1 Nephrology and Dialysis Unit, SM Annunziata Hospital, ASL Toscana Centro, via dell'Antella, 50012 Firenze, Italy

2 Nephrology and Kidney Transplantation Unit, Department of Translational Medicine, University of Piemonte Orientale (UPO), Novara, Italy

3 Nephrology and Dialysis Unit, Versilia Hospital, ASL Nord-Ovest, Lido Di Camaiore, Italy

4 Lab Physiology, Department Translational Medicine, University of Piemonte Orientale (UPO), Novara, Italy

5 Nephrology and Dialysis Unit, ASL Toscana Centro, Pistoia, Italy
6 Nephrology and Dialysis Unit, NSGD Hospital, ASL

Toscana Centro, Firenze, Italy

7 Nephrology and Dialysis Unit, ASL Nord-Ovest, Massa Carrara, Italy

8 Nephrology and Dialysis Unit, ASL VCO, Verbania, Verbano Cusio Ossola, Italy

9 Nephrology and Dialysis Unit, Borgomanero Hospital, ASL NO Novara, Borgomanero, Italy

10 Nephrology and Dialysis Unit, ASL Biella, Biella, Italy

11 Nephrology and Dialysis Unit, ASL Vercelli, Vercelli, Italy

12 Nephrology and Dialysis Unit, ASL Toscana Centro, Empoli, Italy 